\title{
U.S. Drug Importation: Impact on Canada’s Prescription Drug Supply
}

\section{Marv Shepherd*}

Emeritus College of Pharmacy, University of Texas, Austin, United States

\begin{abstract}
Background and objectives: In 2010, I published an article addressing the impact U.S. drug importation will have on the Canadian prescription drug supply. In this article, I reported that only a small proportion of the U.S> prescription volume will have a severe impact on Canadian drug supplies. Currently many U.S. politicians have renewed their interest and are strongly advocating the legalization of prescription drug importation. The objective of this research is to re-examine the issue and estimate the impact U.S. drug importation from Canada will have on the Canadian prescription drug supply.

Methods: Like the 2010 article, the forecasting model created uses baseline numbers for the number of Canadian and U.S. prescriptions dispensed in 2015. Two models were employed: one for all prescriptions and one for only brand name prescriptions dispensed. The number of days to exhaust the Canadian prescription drug supply was estimated by varying the proportion of U.S. prescriptions demanded from Canada.

Results: The model found that if $20 \%$ of the U.S. prescriptions were filled using Canadian prescription drug sources, the 2015 Canadian drug supply would be exhausted in 183 days and this is calculated using an additional supply of $20 \%$. It was believed that U.S. demand for Canadian brand name drugs will be much higher than for generic drugs since generic drugs are substantially cheaper in the U.S. than Canada. Thus, a Canadian brand name drug model was constructed. The results showed that a $20 \%$ demand from the U.S. would deplete the Canadian 2015 brand name drug supply in 201 days.

Conclusion: The results show the risks are high for the Canadian health system if the U.S. were to legalize drug importation. Canada will need to either have a major increase in drug imports or dramatically increase their domestic drug manufacturing. The paper discusses four possible options for Canada to avert a prescription drug shortage.
\end{abstract}

Keywords: Drug; Drug importation; Drug supply; Prescription; Drug manufacturers

\section{Introduction}

In 2010, the Canadian Pharmacists Journal published my paper examining the impact on Canada' prescription drug supply if U.S. legalized drug importation [1]. During the early 2000's, many bills were introduced in U.S. Congress to legalize drug importation primarily from Canada, but other countries were also included. Even both 2008 presidential candidates voiced support for drug importation; however, both candidates softened their stance when it got closer to the November election. The primary reason against drug importation was the threat of importing substandard drug products [2].

Today, the U.S. is facing similar drug importation legislative initiatives. While the current president called for drug importation during his campaign, he has not publicly stated support for the legislative initiatives proposed. On the Federal legislative side, Senator Bernie Sanders' bill, S.469: Affordable and Safe Prescription Drug Importation Act is the major drug importation bill under discussion. Senator Sander's bill is not just about drug importation from Canada, it opens up drug importation from other countries as long as FDA certifies the exporting entity seeking to import drugs into the U.S. Although Sander's bill opens up other countries, the bill's major focus is on obtaining drugs from Canada. In addition, it also allows for both personal and commercial drug importation.

With personal drug importation, a U.S. resident can travel to the country to purchase the drug product, or can purchase the drug product via mail or internet pharmacy website. Pharmacies selling the drug products would have to be "certified" or "authorized" by FDA. The foreign pharmacy would be an FDA "authorized" provider of drugs to U.S. residents; in addition, providers need to be licensed by the country/province where they are located. Drug products need approval from the country where the provider is located.
Currently four states Colorado, Vermont, Utah and Missouri have drug importation legislation pending. Lastly, the State of Maine approved drug importation legislation from Canada, United Kingdom, New Zealand and Australia in 2013, but in 2015, federal district court overturned Maine's drug importation. The District judge ruled that Maine's law infringed on the federal government's regulatory authority. Specifically the judge stated: "Congressional intent to tightly control prescription drug importation," and that the FDC Act "occupies the field of importation of pharmaceuticals from foreign countries" rather than state law [3].

Personal drug importation is illegal in the U.S; however, US officials realize that this is very difficult to enforce. Thus, FDA set up variances for enforcing the law. U.S. Customs officials permit individuals to import drugs as long as the product does not represent an unreasonable risk, it is for personal use only and for non-controlled products and not more than a 90-day supply for commercial volumes and usage, only drug manufacturers and U.S. licensed drug importers are allowed by law to import pharmaceuticals into the U.S.

Sander's bill also legalizes commercial drug importation for U.S. wholesalers, distributors, retail pharmacies, and other licensed

*Corresponding author: Marv Shepherd, Emeritus College of Pharmacy, University of Texas, Austin, United States, E-mail: marvshepherd@austin.utexas.edu

Received January 18, 2018; Accepted January 30, 2018; Published February 05, 2018

Citation: Shepherd M (2018) U.S. Drug Importation: Impact on Canada's Prescription Drug Supply. Health Econ Outcome Res Open Access 4: 146. doi: 10.4172/2471$268 \times / 1000146$

Copyright: @ 2018 Shepherd M. This is an open-access article distributed under the terms of the Creative Commons Attribution License, which permits unrestricted use, distribution, and reproduction in any medium, provided the original author and source are credited. 
commercial pharmacy entities. That is, U.S. commercial entities will be allowed to purchase from foreign "FDA certified" pharmaceutical sources. Thus, the foreign entities seeking to export drugs to the U.S. through Canada will need to be FDA approved. Under Sander's proposed legislation, the drug product needs approval by the foreign country where the exporter is located. For example, if the facility is located in Canada the drug will need to be approved by, Health Canada. The drug does not need FDA approval.

The main driver for drug importation is the price differentiation between U.S. and other countries. In the past, this price differentiation has been primarily with brand name drugs, but now with the price hikes of some generic drugs, generic drugs have entered the debate. The U.S. public wants access to cheaper prescription drugs and with many countries having governmental price controls, some drugs are much cheaper when compared to the U.S [4]. For example, on average brand name drugs in Canada run from $35 \%$ to $55 \%$ lower than in the U.S. Another reason for the price discrepancy between countries is that pharmaceutical manufacturers use a segmented marketing strategy.

That is, they charge different prices to different countries, based on the economic status and purchasing power of the people in the country. This is very similar to firms offering senior citizen discounts at retail establishments, for airplane tickets or in restaurants. The key to segmented or differential marketing is that arbitrage does not occur; that is, the buyers at the low price do not resell the goods. If so, the chance of losing the discount is likely.

As discussed a decade ago, drug importation issues have not changed. The main concerns voiced are assuring drug quality/safety, drug equivalency and reducing the threat of counterfeit drugs. These issues have gained most of the lay press attention. What has changed in the last ten years is the political climate; the American public is very upset with the pharmaceutical industry's high drug prices for brand name products and they see lower drug prices in other countries and want access to these products. One tactic commonly done for pro drug importation is to compare the U.S. drug prices of selected pharmaceuticals with other countries. This is very effective and the outrage voiced by the American public is dominate. There is no doubt that this is the largest change between today compared to ten years ago. It is my belief that if the U.S. were to allow drug importation the demand for pharmaceuticals outside the US will be extremely high.

The one issue that has not received much press attention is the impact U.S. drug importation will have on Canada. My research paper of ten years ago is the only one that has addressed this subject. There have been editorials denouncing U.S. drug importation, but no research. The question to be examined is: Does Canada have the pharmaceutical supplies to become the drugstore for America? A decade ago, I concluded that Canada does not have the drug supply and cannot afford to take the risk of becoming the drugstore for Americans. Canada's drug supply is too limited to support U.S. personal and especially commercial drug importation. Just a small proportion of the U.S. population demanding drugs from Canada would cause a shortage of Canada's drug supplies. Does this still hold true today?

\section{Methodology}

Unless otherwise designated, the dollar amounts expressed will be U.S. dollars (US\$). The designation for Canadian dollars is CN\$. For 2015, the Canadian to U.S. yearly exchange rate used was 1.329 [5]. To convert Canadian dollars to U.S. dollars divide Canadian dollars by the exchange the rate.

\section{North American Industry Classification System (NAICS)}

The NAICS is a consistent system for economic analysis across the three North American Free Trade Agreement partners: Canada, Mexico, and the U. S. NAICS is based on a production-oriented or supply-based conceptual framework in that establishments are grouped into industries according to similarity in the processes used to produce goods or services. For the pharmaceutical manufacturing industries, the primary NAICS code employed in this report is 3254 [6].

\section{Harmonized Schedule (HS)}

The HS is an international classification coding system for imports and exports and the codes are standardized between countries at a basic 6-digit level. HS Schedule B provides export information on 8000 commodities and are based on the HS Schedule Codes. The import statistics provide information on 14,000 commodity classifications. The U.S. International Trade Commission (USITC) administers the HS schedule Codes [7].

Due to the proprietary nature of the import and export information, HS codes are used for specific drug product groups. For example, HS codes represent categorizations of products such as cardiovascular or antidepressant medicaments. The 4-digit HS code most frequently used in this report is HS 3004, which represents pharmaceuticals dispensed in community and hospital pharmacies. The code definition follows:

- Medicaments (not goods of heading no. 3002, 3005 or 3006) consisting of mixed or unmixed products for therapeutic or prophylactic use, put up in measured doses (incl. those in the form of transdermal admin. systems) or packed for retail sale [8].

- This designation was used because it was believed that it best reflects drug products for consumer use, rather than using an overall bulk pharmaceuticals and medicines product code.

- The Canadian Annual Survey of Manufacturers (ASM) was the source for the dollar value of domestic pharmaceutical manufacturing, including exports and imports in Canada.

\section{Model Construction and Results}

In examining the research question, the situation has not changed in the past ten years. Canada's population is one-ninth the size of the U.S. Canada's 2015 population was 35 million, whereas the U.S. population was 318 million. The total number of prescriptions dispensed in Canada in 2015 was 626.7 million or 1.717 million prescriptions per day [9]. The number of U.S. prescriptions dispensed in 2015 was 4.368 billion or 11.967 million a day [10]. The number prescriptions dispensed in the U.S. was nearly seven times larger (6.969) than the number dispensed in Canada.

The average number of U.S. prescriptions dispensed per person in 2015 was 13.735 (4,368 billion prescriptions/318M U.S. population). If $20 \%$ of the U.S. population, which is 64.8 million people, were to get their prescriptions from Canada, the annual prescription demand would be 890.03 million prescriptions per year (64.8 million X 13.735 prescriptions per person per year). This demand is greater than the total number of prescriptions dispensed in Canada in 2015, which were 626.7 million prescriptions.

The daily prescription demand from the $20 \%$ U.S. residents is 2.438 million prescriptions per day. When combined with the Canadian daily demand, the total expected daily demand for prescriptions from Canadian pharmacies is 4.155 million prescriptions a day $(1.717$ 
million prescriptions for Canadians +2.438 million prescriptions from the U.S.). Thus, the daily demand for drugs from Canadian pharmacies wills more than double (4.155 versus 1.717$)$ if just $20 \%$ of the U.S. population obtained their prescription drugs from Canada. The $20 \%$ is a conservative estimate considering the proposed drug importation legislation allows for both personal and commercial importation. It is expected that over time the U.S. demand for prescription drugs from Canada will continue to escalate.

\section{Prescription supply days}

Another way to look at this result is to calculate the number of days the 2015 Canadian prescription drug supply will last if $20 \%$ of Americans obtained their drugs from Canada. Figure 1 presents the mathematical model used to determine the number of supply days for prescription drugs.

626,700,000 Annual Number of 2015 Canadian prescriptions/ [Number of U.S. Prescriptions dispensed daily $(4,368,000,000 / 365) \times$ Proportion of Number Prescription Purchased in Canada+ Number of Canadian Prescriptions Dispensed Daily $(1,717,000)]=$ Days' Supply.

Using the above model, the 2015 Canadian prescription drug supply will last approximately 150.83 days if $20 \%$ of the U.S. prescriptions were sourced from Canada (626,700,000 annual prescriptions dispended in 2015 divided by the daily demand of 2,438,000 additional prescriptions from the U.S. combined with the Canadian daily demand of 1,717,000 prescriptions). The results show that the 2015 Canadian drug supply would be exhausted in approximately five months if just $20 \%$ of the U.S. prescriptions were added and no additional drugs were imported or were manufactured to meet the added demand.

As noted, the above calculation does not include any extra or a surplus supply of prescription drugs nor does it include additional supplies. Pharmacies usually have a small surplus supply; they keep additional supply on hand which must be calculated when considering the time it would take to fully drain the Canadian drug supply. In other words, the total Canadian drug supply is larger than the number of prescriptions dispensed in 2015. To accommodate this, an additional $20 \%$ surplus was included in the model, thus, making the number for Canadian prescriptions dispensed 752.04 million. The 2015 number of drug supply days now becomes 182.20 days, instead of 150.8 days. Thus, the 2015 Canadian prescription drug supply will last approximately six months when the U.S. demand for Canadian prescription drugs is at $20 \%$ when calculated with a $20 \%$ surplus.

Figure 1 depicts the trend in days' supply of prescriptions controlling for the proportion of drugs demanded by the U.S. If $40 \%$ of the U.S. prescriptions came from Canada, the 2015 drug supply in Canada will be exhausted in 116 days.

\section{Model for brand name drugs only}

The demand for prescription drugs by U.S. residents will primarily be for brand name drugs not generic drugs because on average, generic drugs are more expensive in Canada compared to the U.S [11]. One study found that U.S. generic drug prices were $57 \%$ less when compared to Canadian generic drug prices [12]. While the Canadian government has been successful in decreasing their high generic drug prices since 2010, generic drug prices are still lower in many other countries including the U.S. when compared to Canada [13]. In 2015, $68.6 \%$ of the prescriptions dispensed in Canada were for a generic drug (429.916 million generic prescriptions). Generic drug use in the U.S. is much higher. In $2015,88.7 \%$ of the U.S. prescriptions filled used a generic drug $(3,874,416$ billion prescriptions) [14]. Using a similar model as before, the number of supply days for brand name drugs was calculated.

Using the above proportions, $31.4 \%$ or 196.784 million prescriptions were for brand name drugs in Canada. In the U.S., only $11.3 \%$ or 483.584 million prescriptions used brand name products. The brand name daily use numbers for Canada and U.S. were 539,134 prescriptions per day for Canada and 1,352,271 for the U.S. As before, an additional $20 \%$ supply was included to the model. Thus, the total annual number of brand name prescriptions is 236.140 million prescriptions $(1.2 \mathrm{x}$ 196.784 million). As noted above, the daily demand from Canadians for brand name products was 539,134 prescriptions and if $20 \%$ of the U.S. brand name prescriptions came from Canada, the U.S. daily demand would be 270,454 additional brand name prescriptions $(0.2 \mathrm{x}$ $1,352,271$ prescriptions). Thus, the total daily demand for brand name prescriptions is 809,588 brand name prescriptions per day $(270,545+$ $539,134)$. If the $20 \%$ of the U.S. brand name prescriptions came from Canada, the number of supply days for brand name drugs in Canada is 243 days. Figure 2 depicts the number of supply days controlling for the proportion of U.S. brand name prescriptions demanded.

A decade ago, a $20 \%$ demand on the Canadian drug supply by Americans resulted in a 201 day supply before it was depleted. The most likely reason why the supply days increased is that in the last decade fewer and fewer Americans are using brand name drugs. In 2007, $32.7 \%$ of the U.S. prescriptions were for brand name drugs, three times larger than today. Figure 2 shows that a steady decrease in supply days of Canadian brand name drugs as more and more U.S. prescription come from Canada. If $40 \%$ of U.S. brand name prescriptions came from Canada, the 2015 Canadian prescription drug supply would be exhausted in approximately six months unless domestic supplies increased.

\section{Discussion and Implications}

If the U.S. were to adopt drug importation legislation, the results show that the risks are very high for the Canadian Health Care System

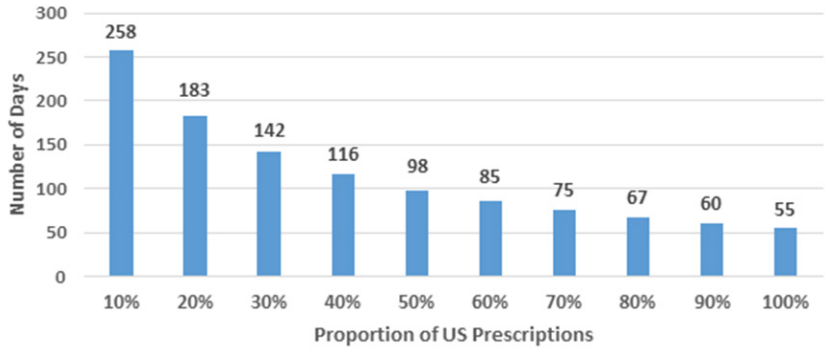

Figure 1: Number of days supply for canadian prescription drugs cotrolling for proportion of U.S. prescripitions demanded.

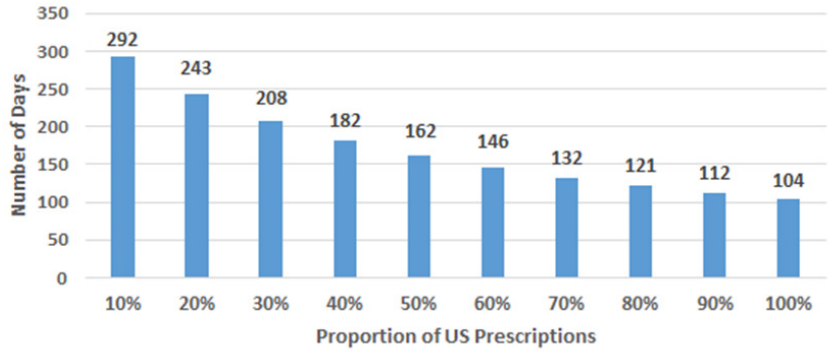

Figure 2: Number of days supply for canadian brand name prescription drugs cotrolling for proportion of U.S. prescripitions demanded. 
and Canadians. Survey evidence shows that obtaining prescription drugs from Canada has strong support by Americans [15,16]. A recent Kaiser poll found that two-thirds of the respondents were in favour of American buying drugs from Canada [17]. As mentioned earlier, four states have legislation proposed to allow drug importation. There is little doubt that if U.S. drug importation became legal, many Americans will indeed purchase pharmaceuticals outside the U.S.

The results of this study were similar to the results of study conducted a decade ago. In 2007, the number of supply days was 155 days whereas in this study the number of supply days was 150 days with a $20 \%$ demand from the U.S. The major difference was in the number of prescription when comparing the number of prescriptions dispensed. In 2007, the U.S. prescription drug market was 8.5 times larger than the Canadian market, but in 2015, the market size differential was seven time larger. One possible reason is that the number of dosage units per prescription dispensed have changed over the last ten years, especially in the U.S. More Americans are receiving 90-day supplies of drugs per prescription for chronic diseases instead of 30-day quantities. The data sources used in this study do not include quantities of drugs dispensed nor do they include names of products, just the number of prescriptions dispensed.

To meet the American demand, Canada does have some options. First, Canada can increase their domestic drug manufacturing output. Second, Canada can increase pharmaceutical imports, although a note of caution U.S. firms may not provide the additional pharmaceuticals to meet the added demand. A third option is for Canadians to continue to look the other way and allow Canadian internet operators to obtain medications from foreign sources. Most likely, some or all of these approaches will be needed to meet the demand. Otherwise, Canada will have a severe prescription drug shortage. There is a fourth option and that is Canada can put a halt to providing their domestic drug supply to American customers.

In 2015, Canada imported US\$ 13.180 billion in pharmaceuticals with US\$ 5.16 billion coming from the U.S. These numbers include bulk and measured dosage form drugs. Probably a better classification is to use the Harmonized System Code 3004 which is for pharmaceuticals "put up in measured doses or packed for retail sale [18]. In 2015, the value of Canadian pharmaceutical imports (HS 3004) was US\$ 7.228 billion and the U.S. was the largest supplier of drugs to Canada with US\$ 2.40 billion. In other words, $33.1 \%$ of the drugs imported by Canada come from the U.S [19]. Figure 3 depicts the trend in Canadian drug imports since 2007. U.S. drug exports to Canada have remained $20 \%$ to $30 \%$ of the Canadian imports for the last decade.

Canadian pharmaceutical manufacturing (NAICS Code 3254) had sales of C $\$ 24.6$ billion (US\$ 18.4 billion) in 2015 with $87.5 \%$ of this

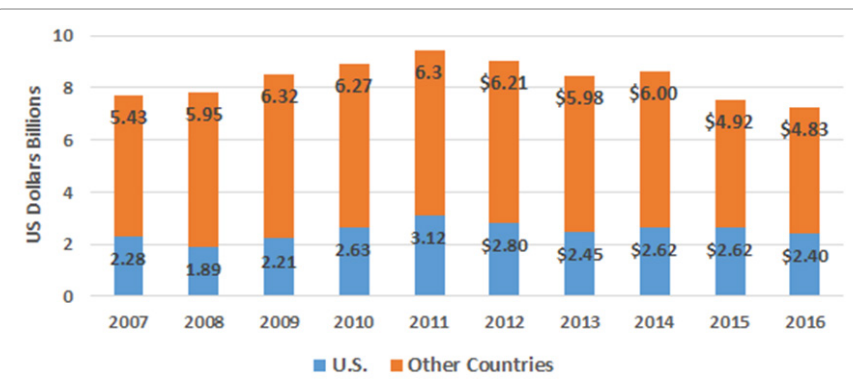

Figure 3: Trend in canadian drug imports from the U.S. and other countries for drug measured dosage forms or packaged for retails use (HS3004) (20072016). total sold to retail pharmacies or US\$16.1 billion [20]. Generic drugs comprise $38.2 \%$ of the total. Their domestic pharmaceutical exports (HS3004) in 2015 were U.S. \$6.3 billion [20] which leaves US $\$ 9.8$ billion for domestic use. Approximately $70 \%$ of the Canadian pharmaceutical exports go to the U.S. Canada manufacturers produce US\$ 9.8 billion of pharmaceuticals for domestic use. When domestic production is combined with pharmaceutical imports and adjusted for re-exports (imported products exported without a substantial change to the product), the result is Canada's pharmaceutical value for domestic use was US $\$ 16.7$ billion in 2015 (US\$9.8 billion Canadian manufactured drugs + US $\$ 7.228$ billion drug imports - US $\$ 0.410$ billion for reexports). The numbers for manufacturing and importation will have to more than double if Canada is to meet U.S. demands.

A word of caution, U.S. pharmaceutical firms may not increase their supplies to Canada due to the arbitrage. Firms may restrict their drug supplies to meet the Canadian public demands only, not U.S. demands. Pharmaceutical manufacturers have agreed to the Canadian governmental price controls, but not when it applies to the much larger U.S. market. The threat is much larger with commercial importation when U.S. based wholesalers and chain pharmacies purchasing large quantities of governmental price controlled pharmaceuticals from Canada for the U.S. market. They purchase the drugs at an artificially produced lower cost and resell them at a much higher cost. Profit taking by the intermediaries (wholesalers, and distributors) and retail outlets could be enormous. There is no guarantee that the savings from drug importation savings will be passed on to the U.S. public.

\section{Canadian pharmaceutical manufacturing and research}

Canadian pharmaceutical manufacturing has had a slow annual growth profile, only growing $0.9 \%$ since 2010 . In addition, from 2000 to 2015 research and development spending by the Canadian pharmaceutical industry has fallen $20 \%$. In 2015, the industry spent CN\$870 million (US\$ 654.6 million) on research and development [21]. As a comparison, U.S. pharmaceutical companies expended US\$ 58.4 billion on research and development [22].

\section{Limitations and problems with added Canadian Drug importation}

When shortages occur in Canada due to the increased U.S demand, the most viable option for Canada is to import added drugs most likely from non-U.S. sources. Some of these suppliers may be high quality suppliers with high quality products; others may be risky and provide substandard or counterfeit pharmaceuticals. Thus, risks to both Canadians and Americans may increase. The last option which cannot be rule out is that Canada limit or halt the exportation of pharmaceuticals to the U.S. This option was frequently mentioned a decade ago when the threat of legalizing drug importation from Canada arose $[23,24]$. In fact, at that time the Canadian Health Minister stated: "Canada cannot be the drugstore for the United States of America $[25,26]$.

\section{Conclusion}

After reviewing the 2015 data, I would not change the conclusions I reached in my 2010 paper. The following is a summary.

- The risks are high for the Canadian health care system if the U.S. were to legalize drug importation, unless Canada has a dramatic increase in domestic drug manufacturing shipments and/or a dramatic increase in the supply of imported prescription drugs. Without these, the threat to the Canadian drug supply is real. Drug shortages will undoubtedly occur. 
Citation: Shepherd M (2018) U.S. Drug Importation: Impact on Canada's Prescription Drug Supply. Health Econ Outcome Res Open Access 4: 146. doi: $10.4172 / 2471-268 x / 1000146$

Page 5 of 5

- Canada faces added risks of importing substandard or counterfeit pharmaceuticals needed to make up for the portion of domestic supply sent to the US. Drug suppliers of varying quality from around the world may be offering and selling drug products to Canada. The risk of obtaining a substandard or counterfeit drug product is higher for both Canadians and U.S. residents purchasing Canadian products because the regulatory control varies widely among source countries.

- The U.S. demand for Canadian drugs may have unexpected results on the Canadian healthcare market, including forcing an increase in Canadian drug prices, especially if shortages become apparent.

- Canada may elect to ban or severely limit drug exports to U.S. residents (personal importation), and, if necessary, ban or limit commercial drug exportation.

The solution for the high drug prices in the U.S. is not importing another country's pharmaceuticals and threatening their drug supplies. As stated in commentary published this year "Canada's drug supply is not a long term solution to America's home-grown drug pricing problem." Solutions are in tackling the problems at home. This means opening up competition, cutting excessive governmental regulations, finding ways to improve and shorten the pharmaceutical development process, shorten the drug approval process especially for generic drugs, improve the transparency of insurance providers, managed care firms and pharmacy benefit management firms, finally investigate and prosecute thus involved in drug price exploitations.

\section{Funding}

Funding for this research provided by the Partnership for Safe Medicines, San Francisco, California.

\section{References}

1. Shepherd M (2010) Effect of US Pharmaceutical Drug Importation on Canadian Pharmaceutical Supply. Can Pharm J 143: 226-233.

2. Nielsen Hobbs (2008) Rx Importation's Appeal for Sen Obama Wanes as Safety Concerns Rise. Pink sheet 70: 14.

3. Karst, Kurt R (2015) District court rules that maine drug importation law is unconstitutional and preempted by FDC act, FDA Law Blog.
4. Robert L, Migliozzi B, Ketaki G (2015) The US pays a lot more for top drugs than other countries.

5. Yearly average exchange rates translating foreign currency to US dollars.

6. National Code Description (2017) 325412 Pharmaceutical Preparation Manufacturing

7. Export.gov (2017) Export product classifications.

8. Foreign trade (2017) Harmonized system codes.

9. Benefits Canada (2017) Looks at the top 25 Drugs.

10. The total number of prescriptions dispensed in the US from 2009 to 2015.

11. Linda B (2014) US Generic Drugs cost less than Canadian Drugs FDA consumer article.

12. Patented medicine prices review board government of Canada generic drugs in Canada international (2017) drug price comparisons and potential cost savings.

13. Patented medicines prices review board national prescription drug utilization system generics 360 (2016) generic drugs in Canada

14. Canadian generic Pharmaceutical association sustainable healthcare market trends.

15. Rachel B (2016) faced with unaffordable drug prices millions buy medicines outside the US Kaiser health news.

16. Dennis T (2016) Americans sick of soaring drug prices health day Harris poll.

17. Jordan R (2016) Poll finds the majority of Americans want restraints on drug prices. Kaiser health news.

18. Canada Border Service Agency (2017) Tariff classification of medicaments including natural health products.

19. Government of Canada, Report-Trade Data Online.

20. Government of Canada (2017) Pharmaceutical Industry Profile.

21. Statista (2017) Research and development expenditure of total US pharmaceutical industry from 1995 to 2015.

22. Best Medicines Coalition (2017) Exportation of medicines from Canada to the United States.

23. Struck D (2005) Canada to restrict exports to U S of prescription drugs Washington.

24. Appleby J (2005) Canada may tighten rules on US drug purchases USA Today. 25. Minerd J (2005) Canada may ban bulk drug exports to U S Medpage Today.

26. Rawson NSB, Louise B (2017) Importation of drugs into the United States from Canada. CMAJ 19: 189. 